\title{
Hemispheric dominance and maze learning
}

\author{
ROBERT ZENHAUSERN and LESLIE NICKEL \\ St. John's University, Jamaica, New York 11439
}

\begin{abstract}
Ten male and 10 female subjects, classified as either right- or left-hemispheric dominant, attempted to learn a 10-blind-alley finger maze. The right-dominant group took fewer trials and less time and made fewer errors than the left-dominant group.
\end{abstract}

Zenhausern (1978) has proposed a model of cognitive functioning, termed hemispheric dominance, based on the differential efficiency of the two cerebral hemispheres. A right-dominant individual is one who tends to experience thoughts in pictoral form and is more efficient at the holistic parallel processing for which the right hemisphere is specialized. A left-dominant individual is one who tends to experience thoughts in verbal form and is more efficient at the logical sequential processing of the left hemisphere.

Several lines of research have lent support to the model. Zenhausern and Repetti (Note 1) have shown that subjects who reported that they thought in pictures scored significantly higher on the right scale than on the left scale of "Your Style of Learning and Thinking" (Torrance, Reynolds, Riegel, \& Ball, 1978), a test measuring the differential preference for and habitual use of the capabilities of the right and left hemispheres. Subjects who reported they thought in words scored significantly higher on the left scale of the same test.

Zenhausern and Gebhardt (1979) have shown that, unlike subjective or objective imagery ability (cf. Ernest, 1977), hemispheric dominance was a good classifying variable in recall and recognition. Several complex interactions emerged that need replication, but the most consistent finding was that left-dominant individuals could retrieve auditorily presented material better than visually presented material, while the opposite was true for right-dominant individuals.

Coleman and Zenhausern (1979), using lateralized retrieval latencies, have shown differences in processing speed and encoding strategies between left- and rightdominant individuals. In this particular task, they found that right-dominant subjects were significantly faster than left-dominant subjects, even with the superiority of the right-dominant individuals on a simple reaction time task partialed out by means of analysis of covariance. In addition, the encoding and retrieval strategies of right-dominant subjects seemed consistent with a parallel pictoral style; that of the left-dominant subjects was consistent with a verbal sequential style.

There is a consistent prediction that flows from this model of hemispheric dominance: If a hemisphere is specialized for a specific function, individuals who are dominant in that hemisphere will do better on tasks related to that function than individuals who are dominant in the contralateral hemisphere. The present study represents an attempt to support that prediction, using maze learning as the task in question. Learning a maze depends on visual-spatial abilities, especially the ability to form a visual representation (cognitive map) of the unseen maze. Since these abilities are usually associated with the right hemisphere, it was expected that right-dominant individuals would surpass leftdominant individuals on this task.

\section{METHOD}

\section{Subjects}

Agreement between a questionnaire developed by Zenhausern and Repetti (Note 1) and at least an 8-point difference between the left and right scores on "Your Style of Learning and Thinking" (Torrance et al., 1978) were used as the criteria for selecting right- and left-dominant subjects. Five males and five females from each dominance participated, for a total of 20 subjects.

\section{Apparatus}

A wooden board $18 \times 12 \times .5$ in. served as the maze. The pathway, cut completely through the board, consisted of circular start and goal areas with 10 blind alleys between the two.

\section{Procedure}

After blindfolding the subject, the experimenter set the maze in front of him or her and placed his or her finger at the starting point. As the subject attempted to reach the goal, the experimenter noted the number and location of blind alleys entered and then recorded the time to traverse the maze. This procedure continued until the subject either ran the maze with no errors or completed 10 trials.

\section{RESULTS AND DISCUSSION}

There were five dependent measures taken on the maze performance: (1) number of trials, (2) total time, (3) time per trial, (4) total errors, and (5) errors per trial. These data for right- and left-dominant males and females can be seen in Table 1 .

Every right-dominant individual was able to achieve an errorless maze run within 10 trials; no left-dominant subject reached this criterion. An analysis of variance with sex and dominance as the independent variables indicated that right-dominant subjects (mean $=6$ ) required fewer trials than left-dominant subjects 
Table 1

Mean Number of Trials, Total Time, Mean Time, Total Errors, and Mean Errors as a Function of Hemispheric Dominance

\begin{tabular}{lccccc}
\hline & $\begin{array}{c}\text { Number } \\
\text { of Trials }\end{array}$ & $\begin{array}{c}\text { Total Time } \\
\text { (Seconds) }\end{array}$ & $\begin{array}{c}\text { Time per } \\
\text { Trial }\end{array}$ & $\begin{array}{c}\text { Total } \\
\text { Errors }\end{array}$ & $\begin{array}{c}\text { Errors } \\
\text { per Trial }\end{array}$ \\
\hline \multicolumn{5}{c}{ Right Dominant } \\
Male & 5.60 & 250.38 & 48.95 & 19.00 & 3.63 \\
Female & 6.40 & 594.19 & 90.80 & 40.40 & 6.13 \\
Mean & 6.00 & 422.29 & 69.88 & 29.70 & 4.88 \\
\multicolumn{7}{c}{ Left Dominant } \\
Male & 10.00 & 947.12 & 94.71 & 69.00 & 6.90 \\
Female & 10.00 & 1110.76 & 111.08 & 62.00 & 6.20 \\
Mean & 10.00 & 1028.94 & 102.90 & 62.50 & 6.55 \\
\hline
\end{tabular}

$($ mean $=10)$ to learn the maze $[F(1,16)=22.70$, $\mathrm{p}<.01]$.

An analysis of variance of total time indicated that right-dominant subjects (mean $=422.28$ ) took significantly less time $[\mathrm{F}(1,16)=22.24, \mathrm{p}<.01]$ than leftdominant subjects (mean $=1,028.94)$, and males $($ mean $=598.75)$ were significantly faster $[F(1,16)=$ $4.95, \mathrm{p}<.05]$ than females (mean $=852.47$ ). Since these differences may have merely been a function of the greater number of trials for the left-dominant individuals, the analysis was repeated using the mean time per trial as the dependent variable. The results were virtually the same: Right-dominant individuals were faster than left-dominant individuals, and males were faster than females.

An analysis of the total number of errors indicated that the right-dominant subjects (mean $=29.7$ ) made significantly fewer errors $[F(1,16)=18.04, p<.01]$ than left-dominant subjects $($ mean $=65.6)$. This difference was not found, however, when the mean number of errors per trial served as the dependent variable.

The data clearly support the hypothesized differences between right- and left-dominant subjects. The rightdominant individuals learned in fewer trials and less time and with fewer errors than did left-dominant individuals, lending further support to the model that associates hemispheric dominance with a differential facility in using the specialized functions of the two cerebral hemispheres.

\section{REFERENCE NOTE}

1. Zenhausern, R., \& Repetti, J. A comparison of two measures of cerebral dominance. Paper presented at the Eastern Psychological Association, Philadelphia, 1979.

\section{REFERENCES}

Coleman, S., \& Zenhausern, R. Processing speed, laterality patterns, and memory encoding as a function of hemispheric dominance. Bulletin of the Psychonomic Society, 1979, 14, 357-360.

Ernest, C. Imagery ability and cognition: A critical review. Journal of Mertal Imagery, 1977, 1, 181-216.

Torrance, E., Reynolds, C., Ball, O., \& Riegel, T. Revised norms-Technical manual for your style of learning and thinking. Athens, Ga: University of Georgia, 1978.

ZENHAUSERN, R. Imagery, cerebral dominance, and style of thinking: A unified field model. Bulletin of the Psychonomic Society, 1978, 12, 381-384.

Zenhausern, R., \& Gebhardt, M. Hemispheric dominance in recall and recognition. Bulletin of the Psychonomic Society, $1979,14,71-73$.

(Received for publication August 28, 1979.) 